\title{
RESEARCH
}

Open Access

\section{Role of Anthocleista vogelii in serum antioxidant defence system in cadmium- induced oxidative stress in Wistar rats}

\author{
Augustine Apiamu ${ }^{1 *}$ (D), Samuel Ogheneovo Asagba ${ }^{2}$ and Nyerhovwo J. Tonukari
}

\begin{abstract}
Background: Cadmium (Cd) toxicity, which runs across the food chain, is chiefly regulated by in vivo antioxidant defence system or through antioxidant supplementation of biological systems predisposed to this environmental stressor. The present study was designed to examine the role of Anthocleista vogelii leaves in Cd-induced oxidative stress in the serum of Wistar rats through the application of response surface methodology (RSM) and biomonitoring of selective responses: malondialdehyde (MDA), catalase (CAT), superoxide dismutase (SOD), glutathione-s-transferase (GST) and peroxidase (POD) activities, respectively. The cold macerated plant leaves were subjected to fractionation process using methanol-hexane-chloroform (3:2:1 v/v) solvent system such that $\mathrm{n}$-hexane fraction with ample antioxidant levels in terms of total phenolic content (TPC) and total flavonoid content (TFC) among others at $p<0.05$ was selected for the study. The study employed central composite design (CCD) with twenty experimental "runs" of male Wistar rats for twenty-eight days, following a week of acclimatization, where n-hexane fraction of $A$. vogelii (NFAV), cadmium chloride $\left(\mathrm{CdCl}_{2}\right)$ and body weights of rats were considered input factors in the study.
\end{abstract}

Results: The study generated five quadratic models, which differed significantly at $p<0.05$ for MDA levels as well as CAT, SOD, GST and POD activities in the sera of Wistar rats. The study revealed that exposure to Cd toxicity caused a marked increase $(p<0.05)$ in serum MDA levels, but a significant inhibition $(p<0.05)$ of serum SOD, CAT, GST and POD activities. However, Cd interaction with NFAV showed marked amelioration of Cd-induced oxidative stress, which was confirmed by significant decrease in serum MDA levels, but significant increase in serum SOD, CAT, GST and POD activities at $p<0.05$ via the response surface plots. The study also confirmed the reliability and adequacy of the models for accurate prediction of the responses since R-squared $\left(R^{2}\right)$ values obtained were greater than $90 \%$.

Conclusion: It was inferred from the present study that the adequacy of the models validated the potency of $A$. vogelii leaves graphically in the amelioration of Cd-induced oxidative stress in the serum of Wistar rats. Hence, the plant was considered a rich source of bioactive compounds with significant antioxidant properties.

Keywords: Anthocleista vogelii, Central composite design, Oxidative stress, Quadratic models, Response surface methodology

\footnotetext{
* Correspondence: austodacademia.edu@gmail.com

'Department of Biochemistry, College of Natural and Applied Sciences,

Western Delta University, P.M.B 10, Oghara, Delta State, Nigeria

Full list of author information is available at the end of the article
} 


\section{Background}

The post-discovery of Cadmium (Cd) in 1817 by a German chemist "Friedrich Stromeyer" raised environmental concerns about the toxic nature of the metal on biological systems, which was increased by industrialization and other anthropogenic activities. $\mathrm{Cd}$ is a confirmed environmental toxicant known to compromise the defence line of antioxidants in favour of pro-oxidation of biological systems by reactive oxygen species (ROS) due to overexposure. These species initiate lipid peroxidation of biomolecules, especially polyunsaturated fatty acids (PUFAs), and with subsequent loss of biological functions of membrane [1-3]. The toxicity initiated by $\mathrm{Cd}$ was reported to be associated with its protracted biological half-life, the potential capacity to interact and replace some metallic cofactors in their enzyme forms and indirect induction of free radicals via Fenton reaction [2-4]. The description of Cd toxicity is historically a function of its relative abundance in soil, which is brought about by transportation and infiltration along the food chain. Food, being a primary source of $\mathrm{Cd}$ exposure to consumers, shows that upon ingestion, it is absorbed through the gastrointestinal tract (GIT), transported and distributed through the blood to other tissues, where it bioaccumulates and elicits deleterious effects. Reports have shown that Cd impairs cellular structure, with consequential onsets of diverse pathologies, which include renal dysfunction, liver problems, erectile dysfunction and many more [2, 5-8]. The onset of these pathologies in tissues may be recognized by high expression of metallothionein (MT) and synthesis of other sulphur-rich proteins. In light of the aforesaid, reports have shown that liver and kidney tissues are fundamental centres of Cd toxicity [8-10].

The fundamental cellular mechanism of $\mathrm{Cd}$ toxicity in biological systems can be traced to several factors. Cuypers et al. [9] reported that $\mathrm{Cd}$ has a high affinity for thiol-rich molecules, especially enzymes or structural proteins, with implicative metabolic alterations. Again, zinc ( $\mathrm{Zn})$, Iron (Fe) and other cationic micronutrients, which are bivalent in nature are considered essential cofactors of metalloenzymes thereby competing with a bivalent $\mathrm{Cd}$ metal under physiological setting by redox displacement reaction or interference with the uptake of these nutrients so as to elicit its toxic action on tissues [2]. Another pivotal mechanism of $\mathrm{Cd}$-induced damage in biological systems is oxidative stress, a phenomenon characterized by excessive synthesis of reactive oxygen species (ROS) with a consequential alteration on the prooxidative-antioxidative pool thereby favouring the prooxidants, and resulting in cellular damage and signal transduction [2]. The excessive generation of ROS triggers the formation of malondialdehyde (MDA), a biomarker of oxidative stress, through lipid peroxidation process with deleterious onsets of diverse pathologies [11].
$\mathrm{Cd}$ is considered as a non-fenton metal, owing to the fact that it lacks the direct capacity to initiate synthesis of reactive oxygen species (ROS). Cd-enhanced synthesis of ROS during exposure was reiterated in literature to be associated with Fenton mechanism. Thus, overexposure to this toxicant may result in the overall compromise of the antioxidant defence system through excessive production of ROS with aftermath effect of oxidative stress on biological systems [2, 3, 12]. The compromise may be a consequence of alteration of enzymatic antioxidant activities during a prolonged exposure, which includes the distortion of catalase (CAT), glutathione-s-transferase (GST), superoxide dismutase (SOD), glutathione reductase (GR) and glutathione peroxidase (GPX) activities respectively, as reported in literature $[13,14]$. The responsibility of empirically based improvement of $\mathrm{Cd}$-induced oxidative stress may be associated with some secondary metabolites with antioxidant properties inherent in plants. The antioxidative function of these intrinsic metabolites of plants can be actualized, if their concentrations are adequate to prevent and downregulate undue synthesis of free radicals, for the enhancement of in vivo antioxidant defence system [15]. However, much is yet to be known about plant-rich metabolites with antioxidant properties, their synthesized amounts and mechanisms of actions respectively. Reports have empirically supported the numeric estimation and qualitative presence of phenolics and flavonoids with antioxidant properties in Anthocleista vogelii [16-18].

A. vogelii, a known genus among fifteen acknowledged forms of anthocleista genera, is reported to have traditional usefulness in the management of various pathologies such as sexually transmitted disease (STDs), metabolic disorders, hypertension, infertility and many more [19, 20]. It belongs to the Gentaniaceae family and is popularly called "Cabbage tree". The ethnobotanical description of $A$. vogelii involves $6-20 \mathrm{~m}$ height, $0.15-0.55 \mathrm{~m}$ stem width, $0.4-1.5 \mathrm{~m}$ leaf length with $0.24-0.45 \mathrm{~m}$ width [21]. The study carried out by Anyanwu et al. [21] showed the significant role played by the plant in obese Wistar rats. The results succinctly showed a marked reduction in body weights, aspartate aminotransferase (AST), alanine aminotransferase (ALT) and alkaline phosphatase (ALP) activities as well as a marked significant increase in antioxidant status of obese animal models relative to control. Anyanwu and his colleagues hereby inferred that $A$. vogelii exhibits high antioxidant efficacy during supplementation, which was attributed to its rich, intrinsic phenolic and flavonoid contents respectively. To this end, the rich antioxidant activity of $A$. vogelii regardless of the aerial parts was reported to be characterized, and this may be attributed to intrinsic bioactive compounds with free hydroxyl groups 
notably; 1-hydroxy-3,7-dimethoxyxanthone, 1-hydroxy-3, 7,8-trimethoxyxanthone, 1,8-dihydroxy-7,8-dimethoxyxanthone, $7 \alpha$-hydroxysitosterol, stigmasterol, secologanin, and sitosterol-3-O- $\beta$-glucopyranoside $[19,22,23]$.

Therefore, the novelty of the present study is aimed at identifying the potentiating antioxidant role of the plant in ameliorating $\mathrm{Cd}$-induced oxidative stress in the serum of male Wistar rats through the application of response surface methodology (RSM). The application of the research tool (RSM) would help in identifying the antioxidant role of the plant as well as the generation of quadratic models for useful and accurate prediction of responses employed in the biomonitoring of $\mathrm{Cd}$-induced oxidative stress in the serum of Wistar rats.

\section{Methods}

\subsection{Chemical reagents}

All chemical reagents used in the present study were analytical grades, and they were purchased from Sigma Aldrich, which is presently known as "Merck". The chemicals include: anhydrous aluminium trichloride $\left(\mathrm{AlCl}_{3}\right)$, ascorbic acid, iron (iii) chloride $\left(\mathrm{FeCl}_{3}\right)$, cadmium chloride $\left(\mathrm{CdCl}_{2}\right)$, chloroform, folin-ciocalteu reagent, gallic acid, methanol, petroleum ether $\left(40-60^{\circ} \mathrm{C}\right)$, potassium ethanoate $\left(\mathrm{CH}_{3} \mathrm{COOK}\right)$, rutin, sodium trioxocarbonate (iv) $\left(\mathrm{Na}_{2} \mathrm{CO}_{3}\right)$, trichloroacetic acid, thiobarbiturate, hydrogen peroxide $\left(\mathrm{H}_{2} \mathrm{O}_{2}\right)$, adrenaline, chloro-2,4-dinitrobenzene (CDNB), glutathione (GSH), pyrogallol, dipotassium hydrogen tetraoxophosphate $(\mathrm{v})\left(\mathrm{K}_{2} \mathrm{HPO}_{4}\right)$ and potassium dihydrogen tetraoxophosphate (v) $\left(\mathrm{KH}_{2} \mathrm{PO}_{4}\right)$ respectively.

\subsection{Experimental animal models}

Twenty male Wistar rats with average weight of $150.00 \pm$ $8.11 \mathrm{~g}$ were procured from the animal house unit of Biochemistry Department of the University of Benin, Benin City, Nigeria, and housed in metabolic cages for the investigational period. They were allowed to acclimatize for a week, fed with pelleted livestock feeds, free access to water ad libitum and 12-12 h light/darkness cycle respectively. Thereafter, the animals were categorized into 20 experimental runs by means of central composite design (CCD) with two replications in a total of 60 experimental rats, and subjected to treatment for 28 days. The use of rat models in the present study was subject to approval by the ethical committee of the Delta State University, Abraka, Nigeria, responsible for the laboratory principles of handling and care of experimental animals in accordance with the European Community Act of 1986.

\subsection{The plant of experimental interest}

After harvest from the environment of Western Delta University, Oghara, Nigeria, the plant was identified and authenticated as "Anthocleista vogelii" at the Department of Botany, University of Benin, Benin City, Nigeria, by Dr. H.A. Akinnibosun. A sample of the plant was deposited in his herbarium with a voucher designation, "UBHa0258".

\subsection{Preparation of crude sample and its fractionation}

Exactly $3.14 \mathrm{~kg}$ were dried at room temperature $27.0 \pm$ $2.0^{\circ} \mathrm{C}$, milled into fine powdery form of uniform sizes by means of a warring mechanical blender, filtered and extracted by cold maceration technique for 4 days using $70 \%$ methanol. The extraction process was consecutively followed in two repetitions for absolute yield of 34.09\% $(1070.42 \mathrm{~g})$. This was obtained by means of a rotary evaporator and stored at $4{ }^{\circ} \mathrm{C}$ in air-tight container for further use. Furthermore, $230.0 \mathrm{~g}$ of crude sample was fractionated by thin-layer chromatography (TLC) aided by a precoated silica gel plate and vacuum liquid chromatography (VLC). The fatty component of the extract was removed using petroleum ether $\left(40-60^{\circ} \mathrm{C}\right)$ type and the impenetrable portion was fractionated using methanol-hexanechloroform, (3:2:1 v/v), solvent system. Upon two repetitions, the respective fractions were further vacuum-dried to a thick brownish-green sticky paste using a rotary evaporator and stored at $4{ }^{\circ} \mathrm{C}$ for further use. Apiamu et al. [16] revealed qualitatively the presence of phenolics and flavonoids in the leaves of $A$. vogelii. In light of this, the bioactive compounds with antioxidant potentials were comparatively quantified in the respective fractions to identifying the fraction required for the in vivo study. The scheme shown in Fig. 1 explains the extraction process of A. vogelii leaves for the study.

\subsection{Evaluation of in vitro total phenolic content (TPC)}

This was estimated following the procedure reported by Ibrahim et al. [24] with minor changes. A 6.5-ml mixture containing $1.0 \mathrm{ml}$ of test sample, $0.5 \mathrm{ml}$ of Folinciocalteu reagent and $5 \mathrm{ml}$ of double distilled water $\left(\mathrm{ddH}_{2} \mathrm{O}\right)$ was incubated for $5 \mathrm{~min}$ at room temperature. To the mixture, $1.0 \mathrm{ml}$ of $0.005 \mathrm{M} \mathrm{Na}_{2} \mathrm{CO}_{3}$ was added and subjected to $60 \mathrm{~min}$ incubation in the dark. Similarly, the assay procedure was done in each case, using $50 \%$ ethanol and gallic acid (GA) as negative and positive controls, and the respective absorbances were read in triplicate determinations with UV-VIS spectrophotometer double beam (Labtech-2802). The intrinsic TPC of test sample (A. vogelii) was assessed in relation to GA standard calibration curve $\left(y=0.0018 x+0.4562 ; R^{2}=\right.$ $0.9168,0-1000 \mu \mathrm{g} / \mathrm{ml}$ ) and expressed as $\mathrm{mg}$ GAE/g of dried sample.

\subsection{Evaluation of in vitro total flavonoid content (TFC)}

This was estimated following the procedure reported by Chang et al. [25] with minor changes. A 5.0-ml mixture 


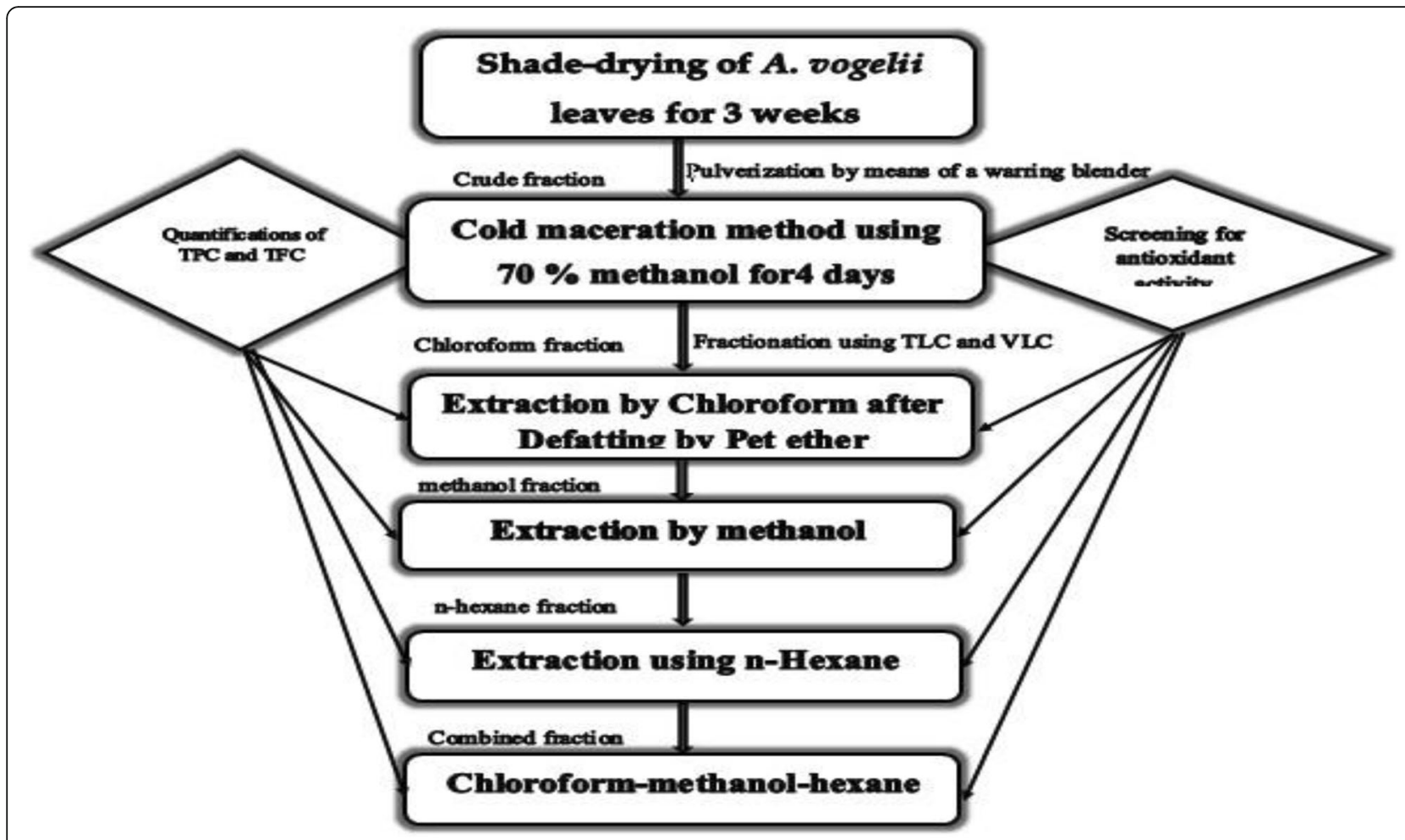

Fig. 1 The order of extraction and fractionation of $A$. vogelii leaves

containing $0.5 \mathrm{ml}$ of test sample, $0.1 \mathrm{ml}$ of $\mathrm{AlCl}_{3}(10 \% \mathrm{w} /$ v), $0.1 \mathrm{ml}$ of $1.0 \mathrm{M} \mathrm{CH}_{3} \mathrm{COOk}$ solution and $4.3 \mathrm{ml}$ of $\mathrm{ddH}_{2} \mathrm{O}$ was subjected to $30 \mathrm{~min}$ incubation. The assay procedure was repeated with $50 \%$ ethanol and rutin (RU) as negative and positive controls, where triplicate absorbances were read in each case using UV-VIS spectrophotometer double beam (Labtech-2802). The intrinsic TFC of test sample (A. vogelii) was assessed in relation to RU standard calibration curve $(\mathrm{y}=0.1255 \mathrm{x}+$ $0.0067 ; \mathrm{R}^{2}=0.966,0-1000 \mu \mathrm{g} / \mathrm{ml}$ ) and expressed as $\mathrm{mg}$ $\mathrm{RUE} / \mathrm{g}$ of dried sample.

\subsection{Experimental design using RSM}

Prior to the design, the study recognized the report of Ayakeme et al. [26] and Virk et al. [27], stating that 15.0 $\mathrm{mg} \mathrm{CdCl} 2$ with reference to body weight of rats, when administered orally, resulted in the induction of oxidative stress. Again, the design measured three input factors or process variables (body weight of rats, plant extract and $\mathrm{Cd}$ dose rates respectively) and response variables such as serum MDA levels and serum enzymatic antioxidant: catalase (CAT), superoxide dismutase (SOD), glutathione-s-transferase (GST) and peroxidase (POD) activities respectively (Table 1). The RSM-CCD was employed in the design of the experiment with 20 sets of experimental runs $(N)$, defined as; $N=2^{k}+2^{k}+$ $n_{o}$, where $\mathrm{k}$ reflects the number of process variables and repetitions with eight factorial, six axial and six centre points. Thus, the general regression model for a seconddegree polynomial is defined hereunder.

$$
\begin{aligned}
Y= & \alpha_{0}+\alpha_{1} \mathrm{~A}+\alpha_{2} \mathrm{~B}+\alpha_{3} \mathrm{C}+\alpha_{11} \mathrm{~A}^{2}+\alpha_{12} \mathrm{~B}^{2} \\
& +\alpha_{13} \mathrm{C}^{2}+\alpha_{21} \mathrm{AB}+\alpha_{22} \mathrm{AC}+\alpha_{23} \mathrm{BC}
\end{aligned}
$$

Such that; $Y$ designates a response variable, $\alpha_{0}, \alpha_{1-3}$, $\alpha_{11-13}$ and $\alpha_{21-23}$ depict fixed intercept term, fixed linear coefficients, fixed-squared coefficients and fixed coefficients of interactions of the regression model. In the

Table 1 Quantification and TLC analysis of bioactive compounds with antioxidant properties in A. vogelii

\begin{tabular}{lccll}
\hline Samples & $R_{\mathrm{f}}$ values & \% Yield & Screening & Quantification \\
\hline Crude fraction & $0.42,0.56$ & 34.09 & TPC & $2.81 \pm 0.50^{*}$ \\
n-Hexane fraction & $0.90,0.72$ & 22.61 & TPC & $263.30 \pm 0.60^{* *}$ \\
& & & TFC & $1159.67 \pm 8.82^{* *}$ \\
Methanol fraction & $0.87,0.70$ & 15.40 & TPC & $241.67 \pm 8.00^{* * *}$ \\
& & & TFC & $1076.33 \pm 8.82^{* * *}$ \\
\hline
\end{tabular}

NB: S. I. units for phenolic and flavonoid contents were determined in $\mathrm{mg} \mathrm{Eq}$ of gallic acid and rutin per gramme of dried sample. Results were expressed as mean \pm SEM of triplicate determinations. TPC of various fractions marked with different asterisks differ significantly $(p<0.05)$ and TFC of various fractions marked with the same asterisks showed no significant difference $(p>0.05)$ 
study, A (plant extract dose rate), B (Cd dose rate) and $C$ (body weight of rats) represent the process variables, and a mixture of this sort; $\mathrm{AB}, \mathrm{AC}$ and $\mathrm{BC}$ is an indication of significant interaction of the variables.

\subsection{Optimization of enzymatic antioxidant defence system}

The optimal activities of antioxidant enzymes in serum were actualized through the application of numerical optimization approach (NOA) on the experimental variables. Thus, plant extract and $\mathrm{Cd}$ dose rates were set at $200 \mathrm{mg} / \mathrm{kg}$ and $15 \mathrm{mg} / \mathrm{kg}$, while the body weights of rats were left in range (100-200 g). The optimization process functions primarily to identifying the significant role played by $A$. vogelii in the improvement of $\mathrm{Cd}$-induced oxidative stress in Wistar rats via minimization of MDA levels.

\subsection{Experimental sampling}

The rats were anaesthetized using chloroform in a desiccator, and whole blood samples were collected by heart puncture into EDTA bottles using hypodermal syringes and centrifuged at $2500 \mathrm{~g}$ for $15 \mathrm{~min}$. The serum obtained from the centrifugation process was properly refrigerated at $4{ }^{\circ} \mathrm{C}$ for further use.

\subsection{Biochemical analysis}

Oxidative stress is monitored through the measurement of malondialdehyde (MDA) levels formed during lipid peroxidation process, following the assay procedure described by Iqbal et al. [28]. The assay procedure described by Aebi [29] and Luck [30] was employed in the assessment of serum CAT activity on the basis of $\mathrm{H}_{2} \mathrm{O}_{2}$ breakdown into $\mathrm{H}_{2} \mathrm{O}$ and $\mathrm{O}_{2}$, respectively. Serum SOD activity was evaluated following the assay method described by Misra and Fridovich [31] via the formation of adrenochrome from auto-oxidation of adrenaline. Serum GST activity was analysed following the method described by Habig et al. [32] through complexation of GSH with Chloro - 2, 4-dinitrobenzene (CDNB) with slight alteration. The assay method described by Reddy et al., [33] was employed in the analysis of serum POD activity and serum total protein was evaluated by the method of Tietz [34].

\subsection{Empirical data analysis}

The Design-Expert Software 10.0.7 (Stat Ease Inc., Minneapolis, USA) was employed in the design of the present study, mathematical modelling, graph plottings, optimization process and statistical analysis. In each case, the quality of developed models was evaluated through analysis of variance (ANOVA) embedded in the software, regression coefficient $\left(R^{2}\right.$ value), predicted $R^{2}$ and adjusted $R^{2}$ values, respectively. The validation of optimum conditions was actualized using the software with consideration of mean values of triplicate result for respective responses, where models at $p<0.05$ were considered significant.

\section{Results}

\subsection{The choice of fraction for RSM-CCD study}

The reduction of in vivo antioxidants' activities during over-exposure to $\mathrm{Cd}$ toxicity may result in the compromise of their defensive role; hence, in vitro supplementation strategy (ISS) may be suggestive during non-affirmative exposure of biological systems to this environmental stressor. Here, the crude leaf extract, methanol and hexane fractions assessed differ significantly $(p<0.05)$ in relation to their TPC and TFC. However, the chloroform fraction was discarded since it qualitatively showed the absence of phenolic and flavonoid compounds. On the basis of their content, the n-hexane fraction showed an ample amount of TPC and TFC with marked significant difference in relation to the other fractions (Table 1). Therefore, the $\mathrm{n}$-hexane fraction was selected for the in vivo study since researchers reported that polyphenols are invaluable bioactive compounds exhibiting antioxidant activity and capacity to chelate metal ions with toxicity tendencies [23].

\subsection{Computation of mean results of responses for modelling}

On the basis of the RSM-CCD, the mean values of responses, which include serum biomarker of oxidative stress (MDA levels) and enzymatic antioxidant (CAT, SOD, GST and POD) activities were computed and subjected to RSM analysis for modelling and optimization processes (Table 2). The analysis revealed that there were no outliers in the mean values of the respective responses.

\subsection{Model fitting}

The application of the RSM analysis generated response quadratic models for biomarker of oxidative stress (MDA levels) and enzymatic antioxidant (CAT, SOD, GST and POD) activities in the serum of Wistar rats under combination of twenty experimental runs with variable experimental conditions, as indicated in Eqs. (2)-(6), to evaluate the relationship between process variables (A-plant extract at $0-200 \mathrm{mg} / \mathrm{kg}$ b.wt of rats, B-CdCl $\mathrm{Cl}_{2}$ at $0-15 \mathrm{mg} / \mathrm{kg}$ b.wt of rats, and C-body weight changes of rats) and each response variable with the elimination of non-significant terms;

$$
\begin{aligned}
Y_{\text {MDA }(\text { mmoles } / \text { mg protein })=} & +37.63-19.18 \mathrm{~A} \\
& +12.49 \mathrm{~B}-9.16 \mathrm{AB} \\
& +3.91 \mathrm{C}^{2}
\end{aligned}
$$


Table 2 Experimental RSM-CCD and results of responses from the present study

\begin{tabular}{|c|c|c|c|c|c|c|c|c|}
\hline \multirow[t]{2}{*}{ Run } & \multicolumn{3}{|c|}{ Process variables } & \multicolumn{5}{|c|}{ Response variables } \\
\hline & A & B & C & MDA & CAT & SOD & GST & POD \\
\hline 1 & 100 & 7.5 & 150 & 37.26 & 34.02 & 56.4 & 41.66 & 63.71 \\
\hline 2 & 0 & 0.0 & 100 & 43.6 & 71.53 & 42.01 & 22.32 & 110.8 \\
\hline 3 & 0 & 15.0 & 100 & 86.1 & 15.31 & 32.1 & 12.6 & 35.47 \\
\hline 4 & 100 & 0.0 & 150 & 29.9 & 85.62 & 50.85 & 21.33 & 124.72 \\
\hline 5 & 100 & 7.5 & 200 & 42.7 & 36.44 & 49.05 & 41.65 & 66.52 \\
\hline 6 & 200 & 15.0 & 100 & 31.13 & 31.86 & 99.3 & 39.89 & 70.69 \\
\hline 7 & 200 & 0.0 & 100 & 25.7 & 88.41 & 73.5 & 22.5 & 132.33 \\
\hline 8 & 200 & 7.5 & 150 & 41.26 & 45.67 & 71.1 & 40.01 & 81.19 \\
\hline 9 & 100 & 15.0 & 150 & 37.35 & 25.73 & 74.25 & 49.70 & 60.19 \\
\hline 10 & 100 & 7.5 & 150 & 35.91 & 36.09 & 54.6 & 40.78 & 64.76 \\
\hline 11 & 100 & 7.5 & 100 & 41.34 & 40.49 & 52.72 & 39.77 & 64.57 \\
\hline 12 & 200 & 15.0 & 200 & 30.69 & 28.95 & 74.85 & 42.47 & 75.65 \\
\hline 13 & 100 & 7.5 & 150 & 35.82 & 30.06 & 53.4 & 37.02 & 58.08 \\
\hline 14 & 100 & 7.5 & 150 & 35.47 & 33.17 & 55.41 & 32.38 & 62.89 \\
\hline 15 & 0 & 15.0 & 200 & 88.6 & 12.57 & 37.65 & 17.75 & 41.22 \\
\hline 16 & 100 & 7.5 & 150 & 36.26 & 41.07 & 47.55 & 34.5 & 65.01 \\
\hline 17 & 0 & 0.0 & 200 & 44.02 & 73.97 & 40.95 & 20.61 & 113.04 \\
\hline 18 & 100 & 7.5 & 150 & 43.14 & 35.15 & 54.91 & 30.22 & 57.81 \\
\hline 19 & 200 & 0.0 & 200 & 22.3 & 92.11 & 70.35 & 27.1 & 142.66 \\
\hline 20 & 0 & 7.5 & 150 & 59.06 & 28.9 & 31.35 & 12.00 & 38.24 \\
\hline
\end{tabular}

$$
\begin{aligned}
Y_{\mathrm{CAT}(\text { units } / \mathrm{mg} \text { protein })=} & +36.34+8.47 \mathrm{~A}-29.72 \mathrm{~B} \\
& +17.21 \mathrm{~B}^{2} \\
Y_{\mathrm{SOD}(\text { units } / \text { mg protein })=} & +53.97+23.18 \mathrm{~A} \\
& +6.73 \mathrm{~B}-7.36 \mathrm{AB}-5.19 \mathrm{BC} \\
& -3.46 \mathrm{C}^{2} \\
& \\
Y_{\mathrm{GST}(\text { units } / \text { mg protein })=} & +36.04+7.31 \mathrm{~A} \\
& +5.67 \mathrm{AB}-11.99 \mathrm{~B}^{2} \\
Y_{\text {POD (units } / \text { mg protein })=} & +62.54 \\
& +16.37 \mathrm{~A}-34.03 \mathrm{~B} \\
& +29.18 \mathrm{~A}^{2}
\end{aligned}
$$

In Table 3, the analysis of variance (ANOVA) for serum MDA levels showed that the quadratic model differs significantly $(F=105.48, p<0.0001)$ and the lack of fit test was considered not significant $(p=0.9121)$, indicating the suitability of the model for adequate prediction. Also, the ANOVA for serum CAT, SOD, GST and POD activity indicated quadratic models with marked significant differences at high $\mathrm{F}$ and low $p$ values, and

\begin{tabular}{|c|c|c|c|c|c|c|c|}
\hline Indicators & Source & Sum of squares & Df & Mean square & F Value & $\begin{array}{l}p \text { value } \\
\text { Prob }>F\end{array}$ & Status \\
\hline \multirow[t]{3}{*}{ MDA } & Quadratic model & 5579.47 & 9 & 619.94 & 105.48 & $<0.0001$ & Significant \\
\hline & Lack of fit & 4.36 & 3 & 1.45 & 0.17 & 0.9121 & Not significant \\
\hline & \multicolumn{7}{|c|}{$R^{2}: 0.9916$, Adj. $R^{2}: 0.9822$, Pred. $R^{2}: 0.9805$, Adeq. precision: 36.692} \\
\hline \multirow[t]{3}{*}{ CAT } & Quadratic model & $10,936.77$ & 9 & 1215.20 & 105.27 & $<0.0001$ & Significant \\
\hline & Lack of fit & 48.70 & 5 & 9.74 & 0.73 & 0.6310 & Not significant \\
\hline & \multicolumn{7}{|c|}{$R^{2}: 0.9896$, Adj. $R^{2}: 0.9802$, Pred. $R^{2}: 0.9711$, Adeq. precision: 33.136} \\
\hline \multirow[t]{3}{*}{ SOD } & Quadratic model & 5049.48 & 9 & 561.05 & 33.78 & $<0.0001$ & Significant \\
\hline & Lack of fit & 99.07 & 4 & 24.77 & 2.46 & 0.1754 & Not significant \\
\hline & \multicolumn{7}{|c|}{$R^{2}: 0.9712$, Adj. $R^{2}: 0.9425$, Pred. $R^{2}: 0.7519$, Adeq. precision: 24.512} \\
\hline \multirow[t]{3}{*}{ GST } & Quadratic model & 1503.56 & 9 & 167.06 & 11.64 & 0.0001 & Significant \\
\hline & Lack of fit & 10.20 & 3 & 3.40 & 0.16 & 0.9172 & Not significant \\
\hline & \multicolumn{7}{|c|}{$R^{2}: 0.9290$, Adj. $R^{2}: 0.8492$, Pred. $R^{2}: 0.6802$, Adeq. precision: 10.507} \\
\hline \multirow[t]{3}{*}{ POD } & Quadratic model & $18,447.59$ & 9 & 2049.73 & 139.41 & $<0.0001$ & Significant \\
\hline & Lack of fit & 93.72 & 5 & 18.74 & 1.76 & 0.2754 & Not significant \\
\hline & \multicolumn{7}{|c|}{$R^{2}: 0.9921$, Adj. $R^{2}: 0.9850$, Pred. $R^{2}: 0.9499$, Adeq. precision: 39.045} \\
\hline
\end{tabular}
the insignificant lack of fit tests for these responses further confirmed the reliability of the models for useful predictions during $\mathrm{Cd}$-induced oxidative stress, where $A$. vogelii played a fundamental role of an antioxidant. Again, the regression coefficient $\left(R^{2}\right)$ of 0.9916, 0.9802, $0.9712,0.9290$ and 0.9921 for serum MDA levels, CAT, SOD, GST and POD activities suggested that 99.16, $98.02,97.12,92.90$ and $99.21 \%$ of the variations observed

Table 3 Analysis of variance (ANOVA) for serum oxidative-antioxidative indicators in relation to input variables 
in experimental data could be accounted for by the quadratic models.

\subsection{Graphical analysis}

The adequacy and precision of the quadratic models for the responses were also checked by diagnostic (predicted vs. actual) plots. The proximity of the actual and predicted values to the regression line indicates the reliability of the models (Fig. 2). Consequently, the high correlation could be explained by the high $R^{2}$ values as well as the closeness of the predicted and adjusted $R^{2}$ values associated with the generated models in Table 3.

The 3-D response surface plots of different shapes generated by the models were employed to describe the relationship between the process variables and the responses under these experimental conditions (Figs. 3, 4, 5, 6 and 7). In each case, two process variables with varying degrees of interactive effects on the responses were considered at fixed state of the third process variable. Thus, increasing dose rate of $\mathrm{CdCl}_{2}$ showed a significant induction $(p<0.05)$ of oxidative stress, characterized by increasing levels of MDA in serum of Wistar rats (Fig. 3). However, the interaction between $\mathrm{CdCl}_{2}$ and A. vogelii (n-hexane fraction) extract indicated a significant improvement on $\mathrm{Cd}$-induced oxidative stress in the serum of Wistar rats at $p<0.05$. Comparatively, the interaction between body weights of rats and plant extract or $\mathrm{CdCl}_{2}$ showed similar effects on serum MDA levels with marked significant difference $(p<0.05)$ characterized by rising contour bridges. Also, the study revealed a significant inhibitory effect on the activities of serum enzymatic antioxidants (CAT, SOD, GST and POD) during exposure to $\mathrm{Cd}$ toxicity, but a co-treatment with plant extract revealed a significant increase $(p<0.05)$ in the activities of antioxidant enzymes, which were evidently established by the rising contour bridges in the response surface graphs, describing the extent of interaction between the process variables (Figs. 3, 4, 5, 6 and 7).

\section{Discussion}

4.1 Appraisal of RSM-CCD in the present study using nhexane fraction for the treatment of $\mathrm{Cd}$-induced oxidative stress in Wistar rats

The protracted environmental hazards initiated by cadmium $(\mathrm{Cd})$ compounds on biological systems, in view of several gradations of exposure, are inevitably encompassing in the areas of toxicological investigations. It was then reiterated in literature that $\mathrm{Cd}$ readily accumulates along the food chain to toxic levels with detrimental effects on biological systems as a result of its prolonged biological half-life, pervasive and soluble nature $[3,35]$. To this end, Cd was considered a known toxicant, whose underlying mechanism of absorption and cellular toxicity was principally reported as a concern to researchers in view of its deleterious effects to microorganisms, plants, and animals $[2,11,36]$. Although, in vivo enzymatic and non- enzymatic antioxidants may offer protection against Cd-induced oxidative stress through a mop-up of excess ROS, but over-exposure to this toxicant was reported to compromise the antioxidant defence system, which seemingly supports lipid peroxidation process in biological systems [10, 37]. Therefore, the use of medicinal plants rich in bioactive compounds with antioxidant activity were highly suggested as an alternative route of amelioration of undue generation of ROS in living organisms by exposure to $\mathrm{Cd}$ toxicity [15]. In the present study, this underscored the need for the use of $A$. vogelii with antioxidant potentials in the amelioration of $\mathrm{Cd}$-induced oxidative stress.

The principal focus of toxicologists in the field of life sciences encompasses the amelioration and/or prevention of excessive generation of ROS brought about by a toxicant and subsequent optimization of the antioxidant defence system of vulnerable biological systems. To actualize this objective in the present study with adequate precision and accuracy, a set of synchronized experimental designs and analyses termed "Response Surface Methodology, (RSM)" encrypted with central composite design (CCD) was employed. The critical statistical analysis, which was done in terms of analysis of variance (ANOVA), indicated quadratic models for serum responses (Table 3). The validation of these regression models for adequate prediction of responses was reported to be a function of its regression coefficient $\left(R^{2}\right)$, lack of fit testing and other instruments of measurement [38]. Thus, serum MDA, CAT, SOD, GST and POD quadratic models presented $R^{2}$ values of 0.9916 , $0.9896,0.9712,0.9290$ and 0.9921 with insignificant lack of fit at 95\% confidence interval (i.e. $p>0.05$ ), which means that the model, in each case, consequently accounts for 99.16, 98.96, 97.12, 92.90 and $99.21 \%$ of data generated for the responses in Table 3. The analysis indicated significant quadratic models for the respective responses $(<0.0001)$, and adequate to denoting the mathematical relationship between variables and to measuring the degree of variability in response variables accounted for by the experimental process variables and their specific interactions [39]. The quadratic models were acknowledged good and adequate for the prediction of the responses, owing to their high $R^{2}$ values, low $p$ values and high $\mathrm{F}$ values, respectively $[38,40]$. It was reported that the magnitude of adjusted and predicted $R^{2}$ values can be applied as a measure of proximity of experimental and predicted values [40, 41]. In the present study, the adjusted and predicted $R^{2}$ values for the respective responses were in close conformity, with indication of high correlation between the experimental and predicted data (Table 3). Thus, it was evidently 


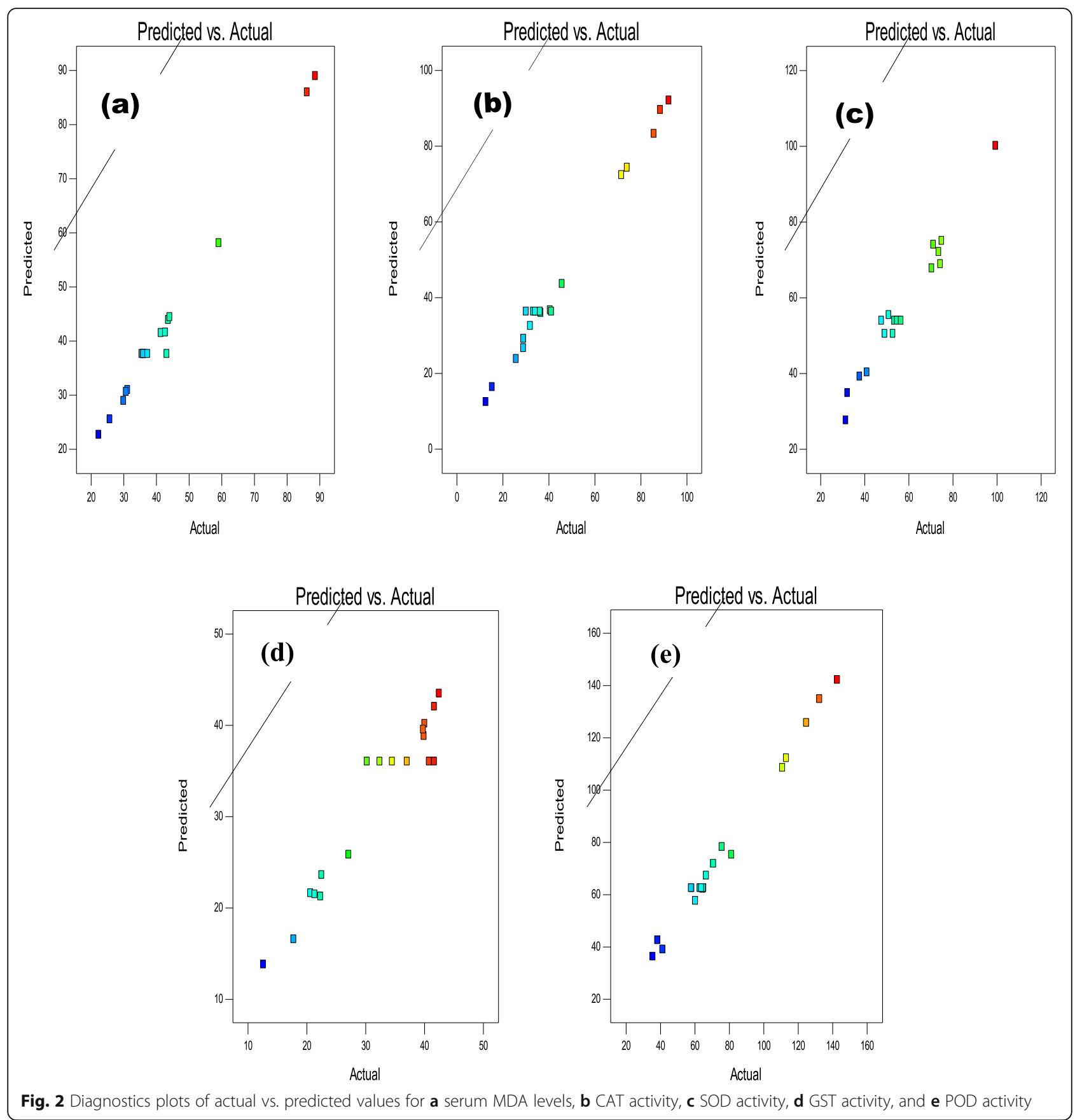

shown in the diagnostic plots of serum MDA levels, CAT, SOD, GST and POD activities (Fig. 2). Kanmani et al. [40] and Ramanan et al. [42] reported the numerical importance of adequate precision to determining which experimental variable generates larger signal in relation to noise during the experiment. It was then inferred that adequate precision of experimental responses greater than four was considered beneficial. Therefore, the adequate precisions; 36.692, 33.136, 24.512, 10.507 and 39.045 for MDA, CAT, SOD, GST and POD quadratic models were suggestive of sufficient signal to noise ratio for adequate prediction (Table 3).

The statistical appraisal of mathematical models is a function of significance and involvement of each process variable using $p$ values [43]. Also, it was stated that the bigger and smaller the magnitudes of $F$ and $p$ values, the more significant is the corresponding coefficients of process variable $[44,45]$. Thus, this necessitated the statistical considerations of the linear, square and interaction coefficients of the respective process variable 

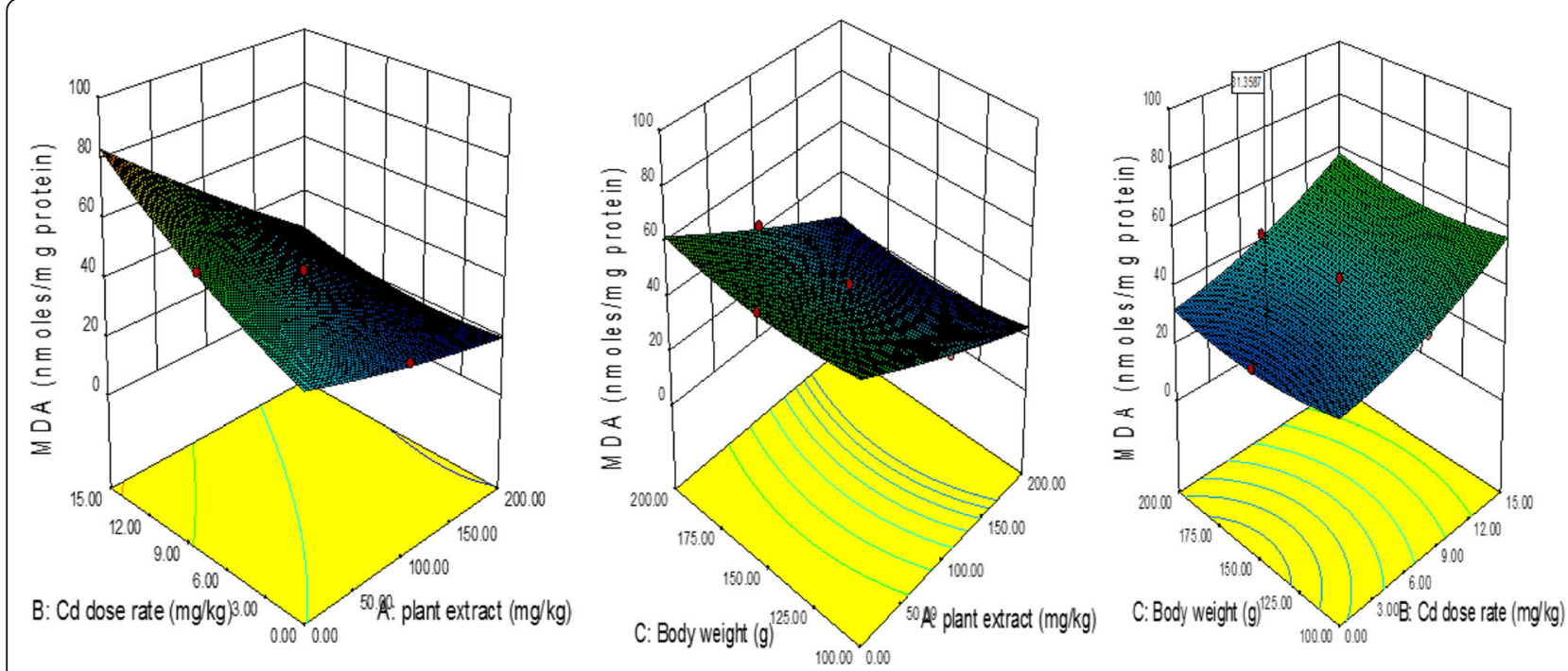

Fig. 3 3-D surface plots for serum MDA levels under the influences of process variables

terms in the modelling course, where the insignificant terms $(p>0.05)$ were eliminated (Eqs. 2-6). The regression models of these sorts were typified graphically in terms of 3-D response surface plots to mean interaction between two process variables at a given time with fixed level of another process variable, assessment of optimal levels and their effects on the response variables [40, 46, 47]. Again, experimental studies on contour lines revealed that it might be saddle, rising bridges or elliptical mounds in nature $[40,48]$. Thus, the plot of Cd dose rate versus plant extract (Fig. 3) is a rising bridge, indicating moderate significant interaction between the two process variables. Optimum MDA levels, as biomarker of oxidative stress, was observed from the plot at $15 \mathrm{mg} /$ $\mathrm{kg} \mathrm{Cd}$ dose rate and zero threshold of the plant extract, which validated the reports report of Ayakeme et al. [26] and Virk et al. [27] that oral administration of 15 $\mathrm{mgCdCl}_{2} / \mathrm{kg}$ b.wt of rats induced oxidative stress. The reduction of MDA levels became significant $(p<0.05)$ at maximum dose rate of plant extract $(200 \mathrm{mg} / \mathrm{kg})$. Therefore, the graphical description of response surface plots shown in Fig. 3 identified the effects of the process variables on the biomarker of oxidative stress. Rao et al. [47] reported that the curvature of response surfaces is a function of well-defined optimal conditions for the variables, but not much variation between single parameters and optimized values was obtained when the response surfaces are flat and symmetrical in proximity to optimal levels. Figures 3, 4, 5, 6 and 7 showed the rising bridges of interactions between process variables, especially $\mathrm{Cd}$

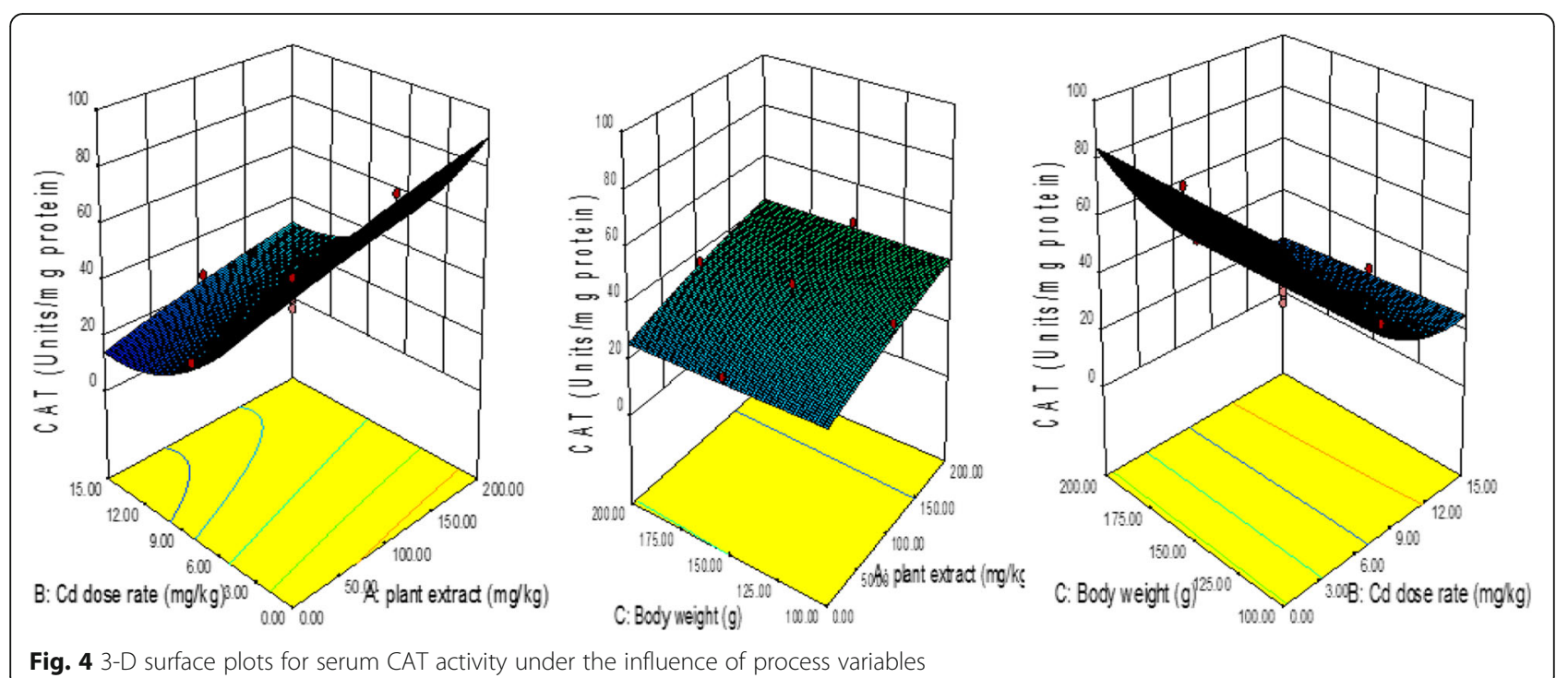

Fig. 4 3-D surface plots for serum CAT activity under the influence of process variables 

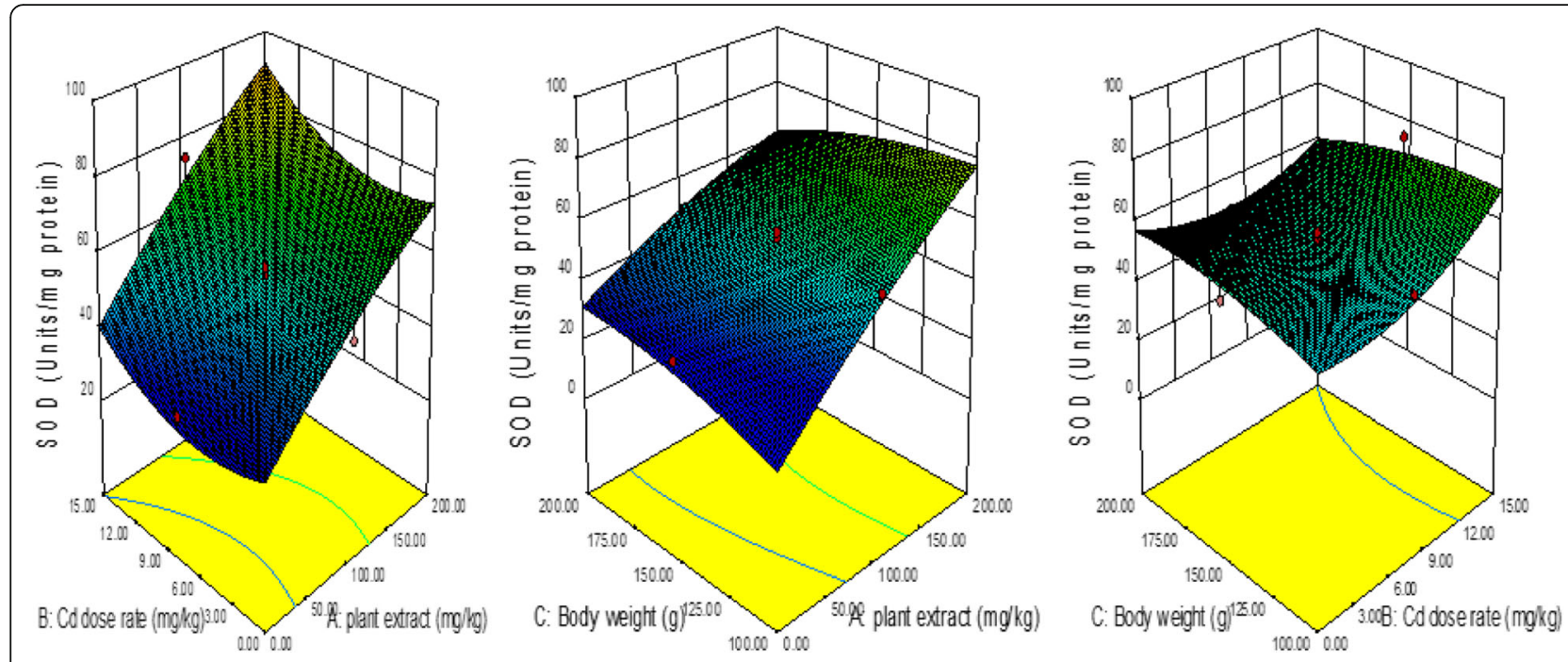

Fig. 5 3-D surface plots for serum SOD activity under the influence of process variables

and plant extract, on enzymatic antioxidant activities. The inhibitory effect on serum CAT activity was significant at $12.0 \mathrm{mg} / \mathrm{kg}$ of Cd, but was alleviated through significant increase $(p<0.05)$ in the dose rate of leaf extract from 100 to $200 \mathrm{mg} / \mathrm{kg}$ (Fig. 4). The rising bridges or saddle points obtained for serum SOD activity indicated that the enzyme activity was inhibited using $6-15 \mathrm{mg} / \mathrm{kg}$ $\mathrm{CdCl}_{2}$ for 28 days, which was absolutely reversed in the presence of the plant extract at peak dose rate of 200 $\mathrm{mg} / \mathrm{kg}$ (Fig. 5). There was significant interaction between $\mathrm{Cd}$ and plant extract, owing to the nature of the contour plots and resulted in maximum serum GST activity. Maximum GST activity ( $36.03 \mathrm{mU} / \mathrm{mg}$ protein) was obtained for $9.0 \mathrm{mg} \mathrm{Cd} / \mathrm{kg}$ b.wt and $200 \mathrm{mg} / \mathrm{kg}$ b.wt of plant extract (Fig. 6). Serum POD activity was significantly inhibited when $\mathrm{Cd}$ dose rate was increased from 6 to $15 \mathrm{mg} / \mathrm{kg}$ with minimum inhibitory effect at $12.0 \mathrm{mg} /$ $\mathrm{kg}$ of $\mathrm{Cd}$ dose rate. However, the inhibitory effect was improved via a significant increase $(p<0.05)$ in the dose rate of leaf extract (100-200 mg/kg) (Fig. 7). The graphical outcomes of the present study conformed with previous reports, showing that exposure to $\mathrm{Cd}$ results in elevated levels of MDA, a derivative of lipid peroxidation and biomarker of oxidative damage [10, 49, 50]. Again, the results proposed that the leaf extract of $A$. vogelii ameliorated Cd-initiated oxidative stress through enhancement of enzymatic antioxidant defence system in male Wistar rats (Figs. 3, 4, 5, 6 and 7). This was attributed to the antagonistic effects brought about by intrinsic phenolic and flavonoid contents of the plant with antioxidant potentials, as characterized by Alaribe, et al. [22], Anyanwu et al. [19] and Valentão
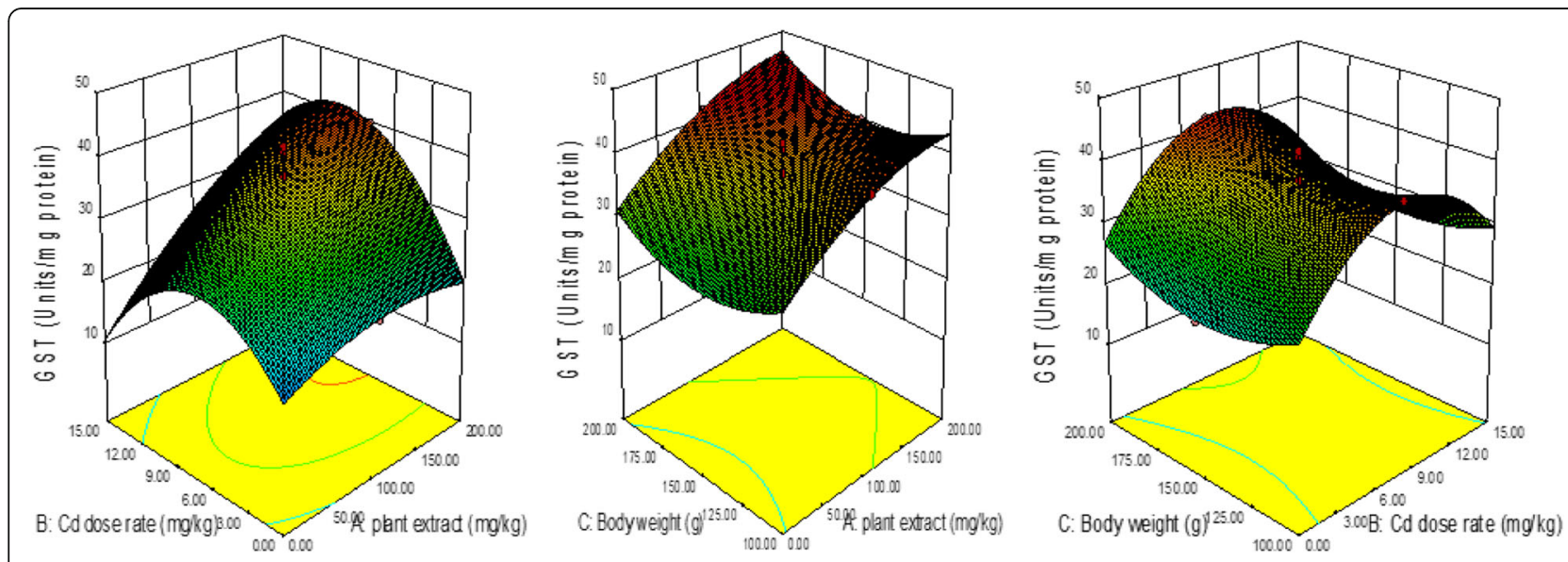

Fig. 6 3-D surface plots for serum GST activity under the influence of process variables 

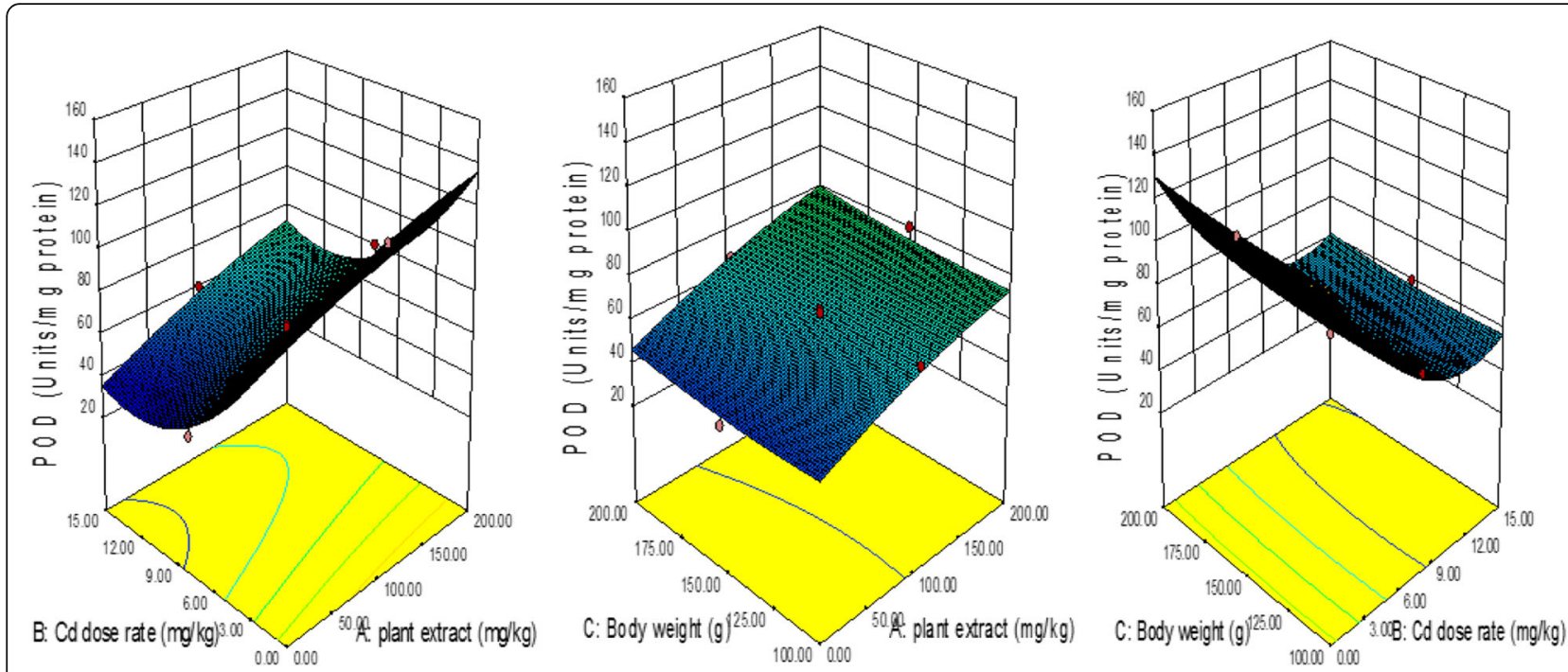

Fig. 7 3-D surface plots for serum POD activity under the influence of process variables

et al. [23], on Cd-induced oxidative damage in the serum of Wistar rats.

\subsection{Confirmation of models}

The essence of the verification study is to show that the developed fitted quadratic models can adequately and correctly be employed in the prediction of the responses' functions, as it pertains to identifying the role of $A$. vogelii in Cd-induced oxidative stress in Wistar rats. Table 4 clearly elucidates that the application of design-expertenhanced models predicted serum MDA levels to be $37.63 \mathrm{mmol} / \mathrm{mg}$ protein and serum CAT, SOD, GST and POD activities to be $36.34,53.97,36.04$ and 62.54 units/mg protein, respectively. Therefore, the application of the set conditions in Table 4 in the laboratory for 28 days confirmed the reliability of the models for the prediction of the responses.

Table 4 Validation of response surface quadratic models

\begin{tabular}{clllll}
\hline Factor & Name & Level & Low level & High level & Std. dev. \\
A & A. vogelii & 100.00 & 0 & 200.00 & 0 \\
B & CdCl $_{2}$ & 7.50 & 0 & 15.00 & 0 \\
C & Body weight & 150.00 & 100.00 & 200.00 & 0 \\
Response & Prediction & Std. Dev & SE $(n=1)$ & $95 \%$ Tl low & $95 \%$ TI high \\
MDA & 37.629 & 5.872 & 2.160 & 7.729 & 67.529 \\
CAT & 36.342 & 3.398 & 1.168 & 20.284 & 52.401 \\
SOD & 53.966 & 5.459 & 1.889 & 27.369 & 80.563 \\
GST & 36.037 & 2.789 & 1.394 & 16.747 & 55.326 \\
POD & 62.537 & 6.725 & 2.312 & 30.749 & 94.326 \\
\hline
\end{tabular}

\section{Conclusion}

The culmination of the present study using RSM-CCD clearly shows successful modelling and optimization of experimental variables for accurate prediction of the responses, and the quadratic models enhanced by 3-D response surface plots established the substantial role played by $A$. vogelii leaves in the improvement of $\mathrm{Cd}$ induced oxidative stress in the sera of Wistar rats, which validated the ample antioxidant property of the plant.

\section{Abbreviations}

$\mathrm{AlCl}_{3}$ : Aluminium trichloride; ALP: Alkaline phosphatase; ALT: Alanine aminotransferase; AST: Aspartate aminotransferase; CAT: Catalase; CCD: Central composite design; $\mathrm{Cd}$ : Cadmium; $\mathrm{CdCl}_{2}$ : Cadmium chloride; CDNB: Chloro-2,4-dinitrobenzene; $\mathrm{CH}_{3} \mathrm{COOK}$ : Potassium ethanoate; $\mathrm{FeCl}_{3}$ : Iron (iii) chloride; GIT: Gastrointestinal tract; GPX: Glutathione peroxidase; GR: Glutathione reductase; GSH: Glutathione; GST: Glutathione-s-transferase; $\mathrm{H}_{2} \mathrm{O}_{2}$ : Hydrogen peroxide; $\mathrm{K}_{2} \mathrm{HPO}_{4}$ : Dipotassium hydrogen tetraoxophosphate; $\mathrm{KH}_{2} \mathrm{PO}_{4}$ : Potassium dihydrogen tetraoxophosphate $(\mathrm{v})$; MDA: Malondialdehyde; $\mathrm{Na}_{2} \mathrm{CO}_{3}$ ): Sodium trioxocarbonate (iv); NFAV: nHexane fraction of Anthocleista vogelii; POD: Peroxidase:

PUFAs: Polyunsaturated fatty acids; ROS: Reactive oxygen species; RSM: Response surface methodology; SOD: Superoxide dismutase; STDs: Sexually transmitted diseases; TFC: Total flavonoid content; TLC: Thin layer chromatography; TPC: Total phenolic content; VLC: Vacuum liquid chromatography

\section{Acknowledgments}

We are warmly grateful to Dr. C.P. Okoli from Biosorption and Water Research Laboratory, Department of Chemistry, Vaal University of Technology, South Africa, who displayed his professional expertise in the training session, involving the application of Design-Expert ${ }^{\dagger}$ software in the present study.

\section{Authors' contributions}

The present research report was a fragment of a doctoral thesis, which was initiated, projected and developed by AA and was chiefly supervised by SOA in consultation with NJT respectively. To this end, all authors have read and approved the final manuscript for publication. 


\section{Funding}

The present research report is not associated with any external funding source rather it was self-funded by the research group.

\section{Availability of data and materials}

All experimental data and materials employed in the development of this research report would be made available upon a reasonable request, but for the meantime, they are kept in the correspondence repository.

\section{Ethics approval and consent to participate}

The use of rat models in the present study was subject to approval by the ethical committee of the Delta State University, Abraka, Nigeria, responsible for the laboratory principles of handling and care of experimental animals in accordance with the European Community Act of 1986.

\section{Consent for publication}

Not applicable

\section{Competing interests}

The present study was not subject to any conflict of interest with any individual or group of persons in terms of financial benefits or constraints. Therefore, we hereby declare that we have no knowledge of plights associated with the publication of this research work

\section{Author details}

${ }^{1}$ Department of Biochemistry, College of Natural and Applied Sciences, Western Delta University, P.M.B 10, Oghara, Delta State, Nigeria. ${ }^{2}$ Department of Biochemistry, Faculty of Science, Delta State University, Abraka, Nigeria.

\section{Received: 14 July 2019 Accepted: 20 September 2019}

Published online: 01 November 2019

\section{References}

1. Arroyo VS, Flores KM, Ortiz LB, Gómez-Quiroz LE, Gutiérrez-Ruiz MC (2012) Liver and cadmium toxicity. J Drug Metab Toxicol S5:001

2. Nair AR, DeGheselle O, Smeets K, Van Kerkhove E, Cuypers A (2013) Cadmium-induced pathologies: where is the oxidative balance lost (or not)? Int J Mol Sci 14:6116-6143

3. Rani A, Kumar A, Lai A, Pant M (2013) Cellular mechanism of cadmiuminduced toxicity: a review. Int J Environ Health Res 24(4):378-399

4. Hideaki S, Yasutake A, Hirashima T, Takamure Y, Kitano T, Waalkes MP, Imamura Y (2008) Strain difference of cadmium accumulation by liver slices of inbred Wistar-Imamichi and Fischer 344 rats. Toxicol in Vitro 22:338-343

5. Asagba SO, Eriyamremu GE (2007) Oral cadmium exposure and haematological and liver function parameters of rats fed a Nigerian-like diet. J Nutr Environ Med 16(3-4):267-274

6. Eriyamremu GE, Asagba SO, Onyeneke EC, Adaikpoh MA (2005) Changes in carboxypeptidase $\mathrm{A}$, dipeptidase and $\mathrm{Na}^{+} / \mathrm{K}^{+}$-ATPase activities in the intestine of rats orally exposed to different doses of cadmium. Biometals 18:1-6

7. The'venod $F$ (2009) Cadmium and cellular signalling cascades:to be or not to be? Toxicol Appl Pharmacol 238(3):221-239

8. Zalups RK, Ahmad S (2003) Molecular handling of cadmium in transporting epithelia. Toxicol Appl Pharmacol 186:163-188

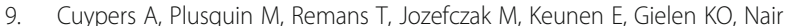
KAR, Munters E, Artois TJ, Nawrot T (2010) Cadmium stress: an oxidative challenge. Biometals 23:927-940

10. Oyinloye BE, Ajiboye BO, Ojo OA, Musa HM, Onikanni SA, Ojo AA (2016) Ameliorative potential of Aframomum melegueta extract in cadmiuminduced hepatic damage and oxidative stress in male Wistar rats. J Appl Pharm Sci 6(07):094-099

11. Said MA, Aiman IA (2014) Oxidative stress versus antioxidants. Am J Biosci Bioengr 2(5):60-71

12. Hart BA, Potts RJ, Watkin RD (2001) Cadmium adaptation in the lung - a double-edged sword? Toxicology 160:65-70

13. Lopez E, Arce C, Oset-Gasque MJ, Canadas S, Gonzalez MP (2006) Cadmium induces reactive oxygen species generation and lipid peroxidation in cortical neurons in culture. Free Radic Biol Med 40:940-951

14. Waisberg M, Joseph P, Hale B, Beyersmann D (2003) Molecular and cellular mechanisms of cadmium carcinogenesis: a review. Toxicology 192(2-3):95-117
15. Flora SJS (2009) Structural, chemical and biological aspects of antioxidants for strategies against metal and metalloid exposure. Oxid Med Cell Long 2:191-206

16. Apiamu A, Asagba SO, Tonukari NJ (2017) In vitro phytochemistry and nutritional status of Anthocleista vogelii. Nigerian J Pharm Appl Sci Res 6(2):44-50

17. Jegede IA, Ibrahim JA, Kunle OF (2011) Phytochemical and pharmacognostic studies of the leaf and stem-bark of Anthocleista vogelii (Planch). J Med Plants Res 5(26):6136-6139

18. Okeke CU, Chinelo AE, Ekwuonye BC, Onwubiko VC, Udechukwu CD, Bibian OA (2015) Comparative study of proximate and phytochemical compositions of Anthocleista Djalonensis Planch. and Anthocleista vogelii A. Chev. (Longaniaceae) in South Eastern Nigeria. Int J Sci Technol 4(7): 377-379

19. Anyanwu GO, Onyeneke CE, Rehman N, Rauf K (2015) Medicinal plant of the genus Anthocleista - a review of their ethnobotany, phytochemistry and pharmacology. J Enopharmacol 175:648-667

20. Olubomehin OO, Abo KA, Ajaiyeoba EO (2013) Alpha-amylase inhibitory activity of two Anthocleista species and in vivo rat model anti-diabetic activities of Anthocleista djalonensis extracts and fractions. J Ethnopharmacol 146:811-814

21. Anyanwu SJO, Innih SO, Onyeneke EC (2014) Liver function and antioxidant status of obese rats treated with ethanol extract of Anthocleista vogelii root bark. Arch Basic Appl Med 2:121-127

22. Alaribe CSA, Coker HAB, Shode FO, Ayoola G, Adesegun SA, Bamiro J, Anyim El, Anyakora C (2012) Antiplasmodial and phytochemical investigations of leaf extract of Anthocleista vogelii (Planch). J Nat Prod 5:60-67

23. Valentão $P$, Andrade $P B$, Silva $E$, Vicente $A$, Santos $H$, Bastos $M L$, Seabra RM (2002) Methoxylated xanthones in the quality control of small centaury (Cen- taurium erythraea) flowering tops. J Agric Food Chem 50:460-463

24. Ibrahim MM, AL Sahl AAA, Alaraidh IA, Al-Homaidan AA, Mostafa EM, ElGaaly A (2015) Assessment of antioxidant activities in roots of Miswak (Salvadora persica) plants grown at two different locations in Saudi Arabia. Saudi J Biol Sci 22(2):168-175

25. Chang CC, Yang MH, Wen HM, Chern JC (2002) Estimation of total flavonoid content in propolis by two complementary colorimetric methods. J Food Drug Anal 10(3):178-182

26. Ayakeme TG, Ibeh GO, Nwinuka MN, Nwachoko NC (2012) Effects of garlic extract on cadmium-induced toxicity in wistar albino rat. Indian J Drugs Dis 1(3):68-73

27. Virk P, Elobeid M, Hamad S, Korany Z, Al-Amin M, Daghestani M, Omer S, Alolayan E, Siddiqui MI, Mirghani NM (2013) Ameliorative effects of Embilica officinalis and Rosmarinus officinalis on cadmium-induced oxidative stress in wistar rats. J Med Plant Res 7(14):805-818

28. Iqbal M, Sharma SD, Zadeh HR, Hasan N, Abdulla M, Athar M (1996) Glutathione metabolizing enzymes and oxidative stress in ferric nitrilotriacetate (Fe-NTA) mediated hepatic injury. Redox Rep 2:385-391

29. Aebi H (1984) Catalase. In: Packer L (ed) Methods in enzymology. Academic press, Orlando, pp 121-126

30. Luck H (1974) Methods in enzymatic analysis. Academic Press, New York

31. Misra HP, Fridovich I (1989) The role of superoxide anion in the autooxidation of epinephrine and simple assay for superoxide dismutase. J Biol Chem 247:3170-3175

32. Habig WH, Pabst MJ, Jakoby WB (1974) Glutathione-S-transferases: the first enzymatic step in mercapturic acid formation. J Biol Chem 249:7130-7139

33. Reddy KP, Subhani SM, Khan PA, Kumar KB (1995) Effect of light and benzyladenine on dark treated graving rice (Oryza sativa) leaves - changes in peroxidase activity. Plant Cell Physiol 26:987-994

34. Tietz NW (1995) Clinical guide to laboratory tests, 3rd edn. W.B. Saunders and Company, Philadephia, pp 518-519

35. Gallagher CM, Chen JJ, Kovach JS (2010) Environmental cadmium and breast cancer risk. Aging 2:804

36. Asagba SO (2013) Cadmium absorption. In: Kretsinger RH, Uversky VN, Permyuakov EA (eds) Encyclopedia of metalloprotein. Springer, New York, Heidelberg, Dordrecht, London, pp 332-336

37. Halliwell B, Gutteridge JMC (2007) Free radicals in biology and medicine, 4th edn. Oxford University Press, New York

38. Granato D, Bigaski J, Castro IA, Masson ML (2010) Sensory evaluation and physicochemical optimisation of soy-based desserts using response surface methodology. Food Chem 121(3):899-906 
39. Hossain MB, Brunton NP, Patras A, Tiwari B, O'Donnell CP, Martin-Diana AB Barry-Ryan C (2012) Optimization of ultrasound assisted extraction of antioxidant compounds from marjoram (Origanum majorana L.) using response surface methodology. Ultrason Sonochem 19:582-890

40. Kanmani P, Karthik S, Aravind J, Kumaresan K (2013) The use of response surface methodology as a statistical tool for media optimization in lipase production from the dairy effluent isolate Fusarium solani. ISRN Biotechnol 13:1-8

41. Prakash O, Talat M, Hasan SH, Pandey RK (2008) Factorial design for the optimisation of enzymatic detection of cadmium in aqueous solution using immobilised urease from vegetable waste. Bioresour Technol 99:7565-7572

42. Ramanan RN, Tan JS, Mohd SM, Ling TC, Tey BT, Arbakariya A (2010) Optimization of osmotic shock process variables for enhancement of the release of periplasmic interferon-a2b from Escherichia coli using response surface method. Process Biochem 45:196-202

43. Thanapimmetha A, Vuttibunchon K, Saisriyoot M, Srinophakun P (2011) Chemical and microbial hydrolysis of sweet sorghum bagasse for ethanol production. World Renew Energy Congr 1:389-396

44. Rengadurai S, Preetha B, Viruthagiri T (2012) Response surface technique for optimisation of parameters for decolorization of reactive red BS using Trametes hiruta. Int J Chem Technol Res 4:21-28

45. Sudamalla P, Saravanan P, Matheswaran M (2012) Optimisation of operating parameters using response surface methodology for adsorption of crystal violet by activated carbon prepared from mango kernel. Sustain Environ Res 22:1-7

46. Lima CJ, De B, Coelho LF, Contiero J (2010) The use of response surface methodology in optimization of lactic acid production: focus on medium supplementation, temperature and $\mathrm{pH}$ control. Food Technol Biotechnol 48:175-181

47. Rao YKSC, Lu SC, Liu BL, Tzeng YM (2006) Enhanced production of an extracellular protease from Beauveria bassiana by optimization of cultivation processes. Biochem Engr J 28:57-66

48. Muralidhar RV, Chirumamila RR, Marchant R, Nigam P (2001) A response surface approach for the comparison of lipase production by Candida cylinidracea using two different carbon sources. Biochem Engr J 9(1):17-13

49. Asagba SO (2010) Alterations in the activity of oxidative enzymes in the tissues of male wistar albino rats exposed to cadmium. Int J Occup Med Environ Health 23:55-62

50. Ashour TH (2014) Preventative effects of caffeic acid phenyl ester on cadmium intoxication induced haematological and blood coagulation disturbances and hepatorenal damage in rats. ISRN Hematol 76:47-54

\section{Publisher's Note}

Springer Nature remains neutral with regard to jurisdictional claims in published maps and institutional affiliations.

\section{Submit your manuscript to a SpringerOpen ${ }^{\circ}$ journal and benefit from:}

- Convenient online submission

- Rigorous peer review

- Open access: articles freely available online

- High visibility within the field

- Retaining the copyright to your article

Submit your next manuscript at $\boldsymbol{\nabla}$ springeropen.com 